\title{
Mathematics and statistics related studies in Indonesia using co-authorship network analysis
}

\author{
Irene Muflikh Nadhiroh a,1,*, Ria Hardiyati a,2, Mia Amelia ${ }^{a, 3}$, Tri Handayani a, ${ }^{a, 4}$ \\ ${ }^{a}$ Research Center for Development of Science and Technology, Indonesian Institute of Sciences, Indonesia \\ ${ }^{1}$ irene.muflikh@gmail.com; ${ }^{2}$ rhardiyati@gmail.com; ${ }^{3}$ mieamelia@gmail.com; ${ }^{4}$ trihandayani.lipi@gmail.com \\ * corresponding author
}

ARTICLE INFO

\section{Article history}

Received October 22, 2017

Revised February 6, 2018

Accepted February 23, 2018

Keywords

Mathematics

Statistics

Scientometrics

Social Network Analysis

Co-authorship

\section{ABSTRACT}

Indonesian scholars have published a numbers of articles in numerous international publications, however, it still lags behind other Singapore, Malaysia and Vietnam. This article performs a bibliometrics analysis and examine the collaboration network in Mathematics and Statistics related subject of scholars with Indonesian affiliation as recorded in Web of Science. In total, based on article publications during 2009-2017, 426 articles were retrieved. Bandung Institute of Technology (ITB) was the affiliation with the highest number of articles (48\%) and number of authors (27\%). Using Social Network Analysis to examine co-authorship networks, this research shows that the co-author network has the highest centrality in the ITB affiliation. Meanwhile, dependency of foreign affiliation is still high, shown as a high percentage (84\% of all articles) of international coauthorship. Co-authorship network of Mathematics and Statistics related studies in Indonesia possesses as a scale-free network and followed the power law distribution. This research showed the achievement of Indonesian scholars of Mathematics and Statistics, and can be used to evaluate the knowledge transfer in these subjects and related areas.

This is an open access article under the CC-BY-SA license.

\section{Introduction}

As the fourth most populous country in the world, Indonesia has great potential because around $43 \%$ of its 250 million people are young or under 25 years old [1] and participation in formal education (higher education level) in 2017 increased $113.78 \%$ compared to 2005 [2]. Indonesian scholars also have published a numbers of articles in numerous international journal, but in fact, it still lacking in publications compared with other ASEAN countries such as Singapore, Malaysia, and Vietnam. Bibliometrics studies can identify and measure the contribution of Indonesian scholars to the advancement of knowledge [3]. Bibliometric research can be used to advance knowledge of science and technology development in relation to social and policy issues [4]. Some of these are citation analysis for assessment of research performance and co-word analysis for mapping science and producing visualization of field of science [5]. Several bibliometrics and scientometrics research carried out in Mathematics and related areas. For example, Arunachalam [6] described mathematics research in India, and Asadi [3] explored the research trend in information theory using a bibliometrics approach. Bibliometrics and Scientometrics approaches are used in a large body of research in order to measure the productivity of scholars in a subject area at a country or international level. Nadhiroh et al. [7] conducted a scientometric study using social network analysis methods to explore central actors and institutions involved in Indonesia scientific publication in Chemistry.

Arunachalam [6], Van Raan [5], and Asadi [3] in their studies only discussed research trends using bibliometric analysis. The study using SNA has been done by Nadhiroh et al. [7] in chemistry but only 
discuss about co-authorship. Although this study also uses SNA but rather explores the co-authorship and research trend based on keyword in different area of mathematics and statistics subjects.

This article carry out a social network analysis and examine the collaboration network, in Mathematics and Statistics related subjects, of scholars, with Indonesian affiliation, as recorded in the Thomson Reuters Web of Science database. This research focuses on the number and growth rate of articles in the Mathematics and Statistics, universities and institution with the greatest number of articles, and the most productive and effective author, authorship and collaboration pattern, and the research trend based on keywords that commonly occurred in the articles.

\section{Method}

This research uses Thomson Reuters Web of Science database using the following search strategy: "Indonesia" in address of affiliation; "Mathematics" or "Statistics" in research area of the articles. The time span limited to 2009-2017, the data was accessed May 13th, 2018. The Thomson Reuters Web of Science database was selected, and according to Wen \& Huang [8], it is the most widely accepted and frequently used database for analysis of scientific publications. This research analyzed scholars who have affiliation located in Indonesia, and included non-Indonesian scholars, with an affiliation address in Indonesia, were included in the analysis.

The analysis has the two sections. First, descriptive data related to the number of authors and the number of articles, performance of authors and institutions, research areas of Indonesian affiliation and the journals used. Second, the collaboration/co-authorship patterns and research trend of Indonesian affiliated scholars in Mathematics/Statistics related studies. Using the metrics of Social Network Analysis (SNA), this research examined the co-authorship network at both author and affiliation levels. Ucinet, Netdraw, and VosViewer software were used in this research to visualize co-authorship networks.

\section{Results and Discussion}

\subsection{Descriptive Data}

In total, 426 publications were retrieved. Duplicate records were excluded; 690 authors from 306 institutions. Table 1 shows the yearly distribution of publications production and the number of authors in mathematics or statistics area of study with Indonesian affiliation.

Table 1. Number of articles and authors in Mathematics/Statistics scientific publication of authors with Indonesian affiliation

\begin{tabular}{cccc}
\hline Year & Number of Publications & Number of Authors & $\begin{array}{c}\text { Ratio } \\
\text { (Author/Articles) }\end{array}$ \\
\hline 2009 & 19 & 54 & 2.84 \\
2010 & 20 & 65 & 3.25 \\
2011 & 24 & 68 & 2.83 \\
2012 & 19 & 51 & 2.68 \\
2013 & 36 & 107 & 2.97 \\
2014 & 36 & 112 & 3.11 \\
2015 & 130 & 436 & 3.35 \\
2016 & 64 & 209 & 3.27 \\
2017 & 78 & 293 & 3.76 \\
\hline
\end{tabular}

The number of authors grew significantly (110\%) in 2013 then grew even higher in 2015 (283\%) but with a decline back to the average growth rate of publications and authors (Fig. 1). Bandung Institute of Technology (ITB) was the affiliation with the highest number of publications and number of authors. The second and third affiliation with the highest number of publications are Gadjah Mada University (UGM) and Sepuluh November Institute of Technology. Even though, number of authors of UGM is less than number of authors of Sepuluh November Institute of Technology (Table 2). 


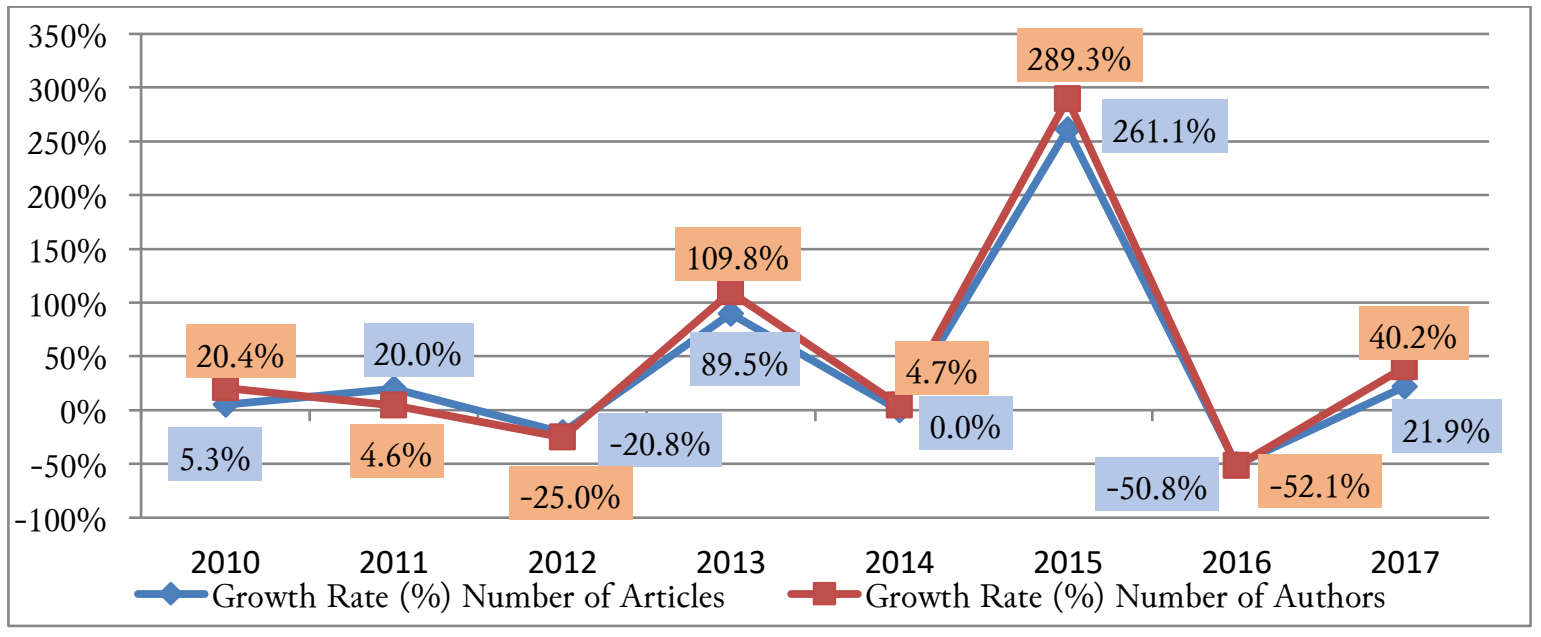

Fig. 1. Growth rate of number of articles and authors

Table 2 shows the number of author and articles from ITB are much higher than other institutions, $18.3 \%$ from total number of authors and $32.4 \%$ from total number of articles, and therefore the highest author/article ratio of 1.85. ITB was the first university with a mathematics faculty in Indonesia and may have affected the quality of human resource and network connection of scholars.

Table 2. Number of authors and articles by affiliation (The Big 10), year 2009-2017

\begin{tabular}{|c|c|c|c|c|c|c|}
\hline No & Affiliation Name & $\begin{array}{l}\text { Number } \\
\text { of Authors }\end{array}$ & $\%$ & $\begin{array}{l}\text { Number of } \\
\text { Publications }\end{array}$ & $\%$ & $\begin{array}{c}\text { Ratio } \\
\text { (Authors/ } \\
\text { Publications) }\end{array}$ \\
\hline 1 & $\begin{array}{l}\text { Bandung Institute of Technology } \\
\text { (ITB) }\end{array}$ & 255 & 18.3 & 138 & 32.4 & 1.85 \\
\hline 2 & $\begin{array}{l}\text { Sepuluh November Institute of } \\
\text { Technology (ITS) }\end{array}$ & 102 & 7.3 & 41 & 9.6 & 2.49 \\
\hline 3 & Gadjah Mada University (UGM) & 95 & 6.8 & 50 & 11.7 & 1.90 \\
\hline 4 & $\begin{array}{l}\text { Bogor Agricultural University } \\
\text { (IPB) }\end{array}$ & 51 & 3.7 & 25 & 5.9 & 2.04 \\
\hline 5 & University of Indonesia (UI) & 27 & 1.9 & 14 & 3.3 & 1.93 \\
\hline 6 & Hasanuddin University & 26 & 1.6 & 19 & 4.5 & 1.37 \\
\hline 7 & Bina Nusantara University & 20 & 1.4 & 10 & 2.3 & 2.00 \\
\hline 8 & Jember University & 19 & 1.4 & 10 & 2.3 & 1.90 \\
\hline 9 & University Kebangsaan Malaysia & 18 & 1.3 & 10 & 2.3 & 1.80 \\
\hline 10 & Brawijaya University & 18 & 1.3 & 11 & 2.6 & 1.64 \\
\hline
\end{tabular}

Table 3 shows the domination of ITB in the international publication of mathematics and statistics related area in Indonesia. Eight of the top 10 authors are from ITB. Edy T Baskoro (ITB) is author with the highest number of articles (30), followed by his ITB colleagues ANM Salman (15).

Table 3. Top 10 number of articles by Indonesian affiliation scholars, year 2009-2017

\begin{tabular}{clccc}
\hline No & \multicolumn{1}{c}{ Scholars Name } & Affiliation & $\begin{array}{c}\text { Number of } \\
\text { Articles }\end{array}$ & \% \\
\hline 1 & Baskoro, E. T. & ITB & 30 & 7 \\
2 & Salman, A. N. M & ITB & 15 & 3.5 \\
3 & Wijayanti, Indah Emilia & UGM & 14 & 3.3 \\
4 & Miller, Minka & ITB & 14 & 3.3 \\
5 & Gunawan, Hendra & ITB & 13 & 3.1 \\
6 & Bahri, Mawardi & Hasanuddin University & 11 & 2.6 \\
7 & Pudjaprasetya, S. R. & ITB & 10 & 2.3 \\
8 & Astuti, Pudji & ITB & 10 & 2.3 \\
9 & Assiyatun, Hilda & ITB & 10 & 2.3 \\
10 & Soewono, Edy & ITB & 8 & 1.9 \\
\hline
\end{tabular}


Research area variables in Thomson Reuters Web of Sciences are article based, and indicate the subject area of each article. Table 4 shows that most articles in Mathematics and Statistics publications related studies had mathematics (77\%) as the key research area with Computer Science (3\%), Engineering (5\%) and Physics (2\%) as the most common related research areas in mathematics/statistics articles published by Indonesian affiliation scholars.

Table 4. Research area of Indonesian affiliation scholars articles in Mathematics and Statistics related are of studies, year 2009-2017

\begin{tabular}{|c|c|c|c|}
\hline No & Research Area & $\begin{array}{l}\text { Number of } \\
\text { Articles }\end{array}$ & $\%$ \\
\hline 1 & Mathematics & 328 & 77 \\
\hline 2 & Computer Science; Mathematics & 13 & 3 \\
\hline 3 & Engineering; Mathematics & 11 & 3 \\
\hline 4 & Engineering; Mathematics; Mechanics & 10 & 2 \\
\hline 5 & Mathematics; Physics & 7 & 2 \\
\hline 6 & Mathematics; Science \& Technology -Other Topics & 5 & 1 \\
\hline 7 & Engineering; Operations Research \& Management Science; Mathematics & 5 & 1 \\
\hline 8 & Mathematics; Mechanics & 3 & 1 \\
\hline 9 & $\begin{array}{l}\text { Automation \& Control Systems; Operations Research \& Management Science; } \\
\text { Mathematics }\end{array}$ & 3 & 1 \\
\hline 10 & Operations Research \& Management Science; Mathematics & 3 & 1 \\
\hline
\end{tabular}

Table 5 shows that $12 \%$ of all articles in the Mathematics and Statistics studies area, by Indonesian affiliation scholars, were published in International Journal of Applied Mathematics 7 Statistics (19\%) and JP Journal of Algebra Number Theory and Applications (3\%).

Table 5. Journals used by Indonesian affiliation scholars to publish two or more articles in Mathematics and Statistics related area of studies, year 2009-2017

\begin{tabular}{clcc}
\hline No & \multicolumn{1}{c}{ Journal } & $\begin{array}{c}\text { Number of } \\
\text { Articles }\end{array}$ & $\%$ \\
\hline 1 & International Journal of Applied Mathematics \& Statistics & 82 & 19 \\
2 & JP Journal of Algebra Number Theory and Applications & 14 & 3 \\
3 & Utilitas Mathematica & 13 & 3 \\
4 & Applied Mathematics and Computation & 10 & 2 \\
5 & Discrete Mathematics & 10 & 2 \\
6 & Applied Mathematical Modelling & 9 & 2 \\
7 & East Asian Journal on Applied Mathematics & 9 & 2 \\
8 & Journal of the Indonesian Mathematical Society & 8 & 2 \\
9 & Malaysian Journal of Mathematical Sciences & 8 & 2 \\
10 & Ars Combinatoria & 8 & 2 \\
\hline
\end{tabular}

\subsection{Collaboration Network}

The average ratio of authors by article during 2009-2017, is 3.1 (Table 1), meaning that there were, on average, three authors of every article. Only 40 articles (9\%) have one author, the rest are articles with multiple authors. on the other hand, 84\% (359) of all articles produced are by collaboration works between Indonesian affiliation scholars and non-Indonesian scholars. Only 16\% (67) articles were produced by Indonesian affiliation scholars without international collaboration which showed the high dependency of Indonesian affiliation scholars on foreign scholars to publish their work in international 
journals. Percentage of collaboration articles increased in the past five years parallel with the increase of number of articles (Fig. 2).

A deep comprehension of the dynamics of scientific collaboration in Mathematics and Statistics related studies of Indonesian affiliation scholars can be carried out using Social Network Analysis. This analysis will portray the links of each scholar and the relative adjacency of other scholars. Abbasi and Altmann [9] conclude that using SNA can help people understand how to share the knowledge via the social network and evaluate the performance in the individual, group, or entire networks. The node of the graph represents the actor, whereas, in this study, node represents the author [10]. In this article, edge is the co-authorship relationship between the authors in these studies.

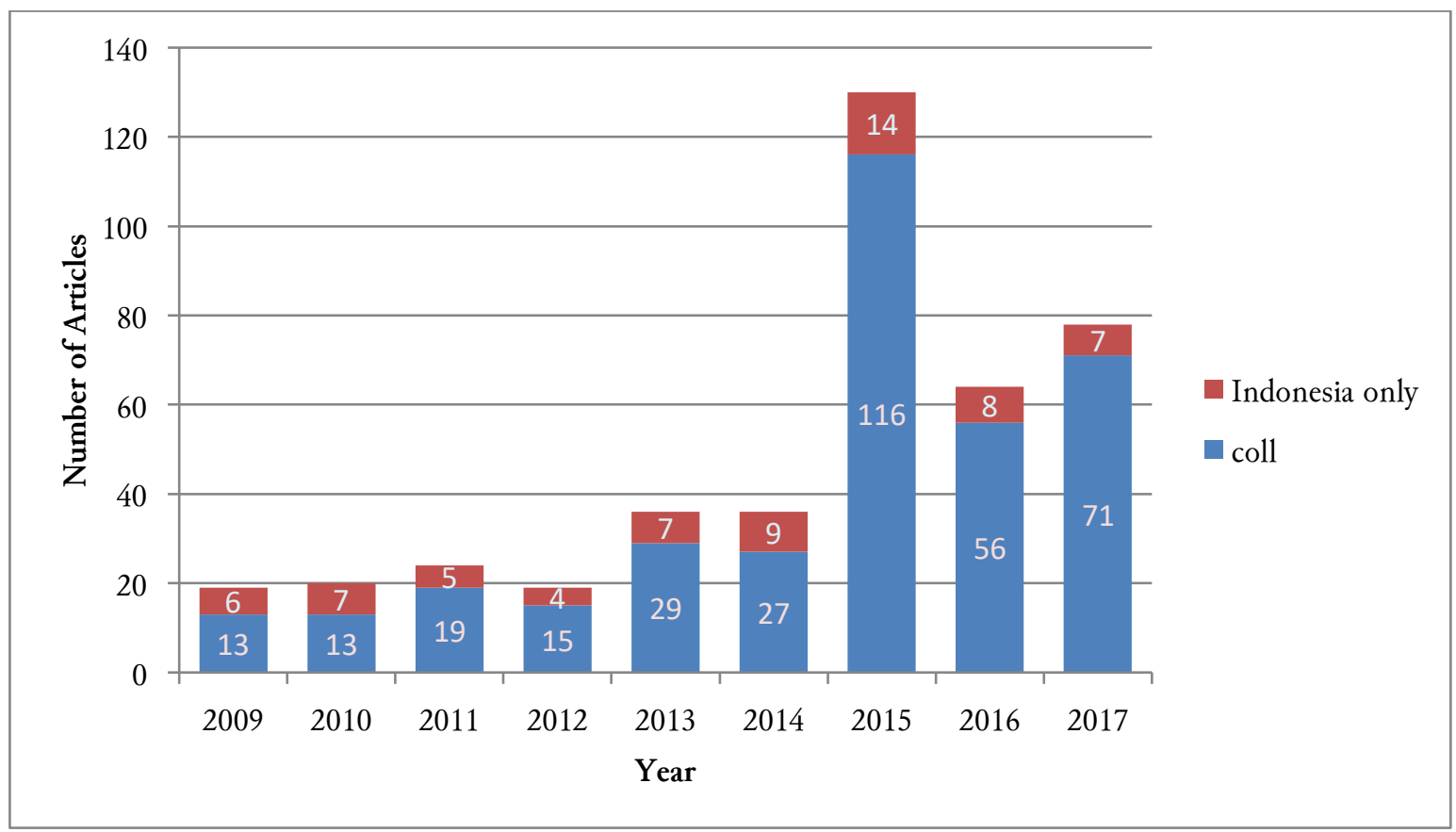

Fig. 2. Distribution of articles produced by collaboration works between Indonesian affiliation scholars and foreign affiliation scholars

SNA has been widely used to explore the co-authorship network in scientific publications at both country and/or area level. For example, Glanzel \& Schubert [11] analyzed scientific networks through co-authorship. Mena-Chalco et al. [12] studied the co-authorship network in Brazil. Alhaider et al. [13] studied the co-authorship network in the Pharmacy area in United Arab Emirate. Sorensen et al. [14] studied the co-authorship network in the research of Alzheimer disease. $\mathrm{Li} \& \mathrm{Li}$ [15] examined the pattern and evolution of co-authorship in China's humanities and social sciences. Yan et al. [16] mapped co-authorship networks in library and information science in China.

SNA metrics measure different levels within a network. Macro-level metrics used to identify the global character of the network [16] and micro-metrics that measure sub-networks of such as individuals (e.g. journals or scholars) and groups (e.g. scholars within a specific institution or a specific group of scholars within an institution). Table 6 shows the network description of co-authorship network of Indonesian affiliation scholars in three networks: all authors in the network, ITB network as a subset of all authors and a network of a big cluster of ITB authors. Network description uses metrics such as network density (ND), degree centrality (DC), closeness centrality (CC) and betweenness centrality (BC). The mean degree centrality reflects the average number of authors that have co-authors in the network.

The Network Density (ND) describes the portion of the potential connection in a network that are actual connections. A potential connection is a connection that could potentially exist between two nodes-regardless of whether or not it actually does. By contrast, an actual connection is one that exists. The network density of all authors is $0.7 \%$, the analysis showed that the total number of potential 
connections between these authors is 475,410 . Of those potential connections, there are only 3,084 actual connections, therefore the network density was $0.7 \%$. The network density of ITB sub-network was $2 \%$ and the big cluster of ITB network was $5.4 \%$.

The mean Degree Centrality (DC) of the 3 networks was 5 or 4, which means that co-authorship of Mathematics and Statistics related studies of Indonesian affiliation scholars is very low. As a comparison, this result is quite similar with Grossman [17] and Newman [18] found, the average number of coauthors in the co-authorship network of Mathematical Review Journal during 1940-2009, had a DC 2.9 or 3 co-authors per each author. Meanwhile, Brunson et al. [19] examined the co-authorship network of Mathematical Review Journal during 1985-2009 and they found the mean number of co-authors in the co-authorship network had a DC of 4.1. The standard deviation of DC reflects the variation in the number of authors that have co-authors in the network.

Table 6. Network statistics descriptive for three co-authorship networks of Indonesian affiliation scholars in Mathematics and Statistics related studies

\begin{tabular}{|c|c|c|c|}
\hline Network Description & All Author & ITB network & Big cluster of ITB's \\
\hline Number of Authors & 690 & 210 & 98 \\
\hline Number of ties & 3084 & 858 & 510 \\
\hline \multicolumn{4}{|l|}{ Degree Centrality (DC) } \\
\hline Mean of DC & 5 & 4 & 5 \\
\hline Minimum of DC & 1 & 1 & 1 \\
\hline Maximum of DC & 79 & 47 & 47 \\
\hline Standard deviation of DC & 5 & 5 & 6 \\
\hline \multicolumn{4}{|l|}{ Closeness Centrality (CC) } \\
\hline Mean of CC & 442 & 1512 & 280 \\
\hline Minimum of CC & 1 & 1082 & 162 \\
\hline Maximum of CC & 2485 & 1873 & 456 \\
\hline Standard deviation of CC & 572 & 301 & 53 \\
\hline \multicolumn{4}{|l|}{ Betweenness Centrality (BC) } \\
\hline Mean of BC & 1 & 70 & 91 \\
\hline Minimum of BC & 0 & 0 & 0 \\
\hline Maximum of BC & 10 & 3173 & 2300 \\
\hline Standard deviation of $\mathrm{BC}$ & 3 & 326 & 333 \\
\hline Network Density & $0.7 \%$ & $2.0 \%$ & $5.4 \%$ \\
\hline
\end{tabular}

The Closeness Centrality metric (CC) is based on the geodesic distances between nodes in a network map and is the average geodesic distance that a node is from all other nodes as shown in the network map. CC measures the closeness between the actors/nodes and a measure of how fast information spreads from a given node to other reachable nodes in the network The initial idea of this measure is referred to as a central actor of a network if it can interact with other actors more easily and quickly. Associated with the flow of information, a central actor, who has close relations with other actors, will be more productive as the actor can access the information due to the shorter lines of communication. The mean CC reflects closeness between the actors. If we compare the value of CC in three networks, network with the best closeness was the network with the lowest CC's score. Smaller CC indicates the better network; means between actors in the co-authorship relation tend to be closer to each other. 
The Betweenness Centrality (BC) of a node reflects the amount of control that this node exerts over the interactions of other nodes in the network. BC shows the average actor in interceding on geodesic distance between actors in the network. Individuals with the highest $\mathrm{BC}$ are considered as an actor in control of the flow of information within the network. ITB network was the network with the lowest of CC, means among authors not well connected to each well and actors numbers who have a role to mediate information between actors, geodesic distance between actors would be small and occur geodesic distance is equal to zero, because between the two actors are not connected to each other because they are in different subgroups.

Fig. 3 shows Degree Centrality (DC) distribution of Mathematics and Statistics related studies of Indonesian affiliation scholars. Twenty-five percent of authors in the network had two co-authors, whereas twelve authors had twenty for 79 co-authors. Yan et al. [16] explain that there are "hub" authors that have many co-authors or ties with many authors compared with other authors.

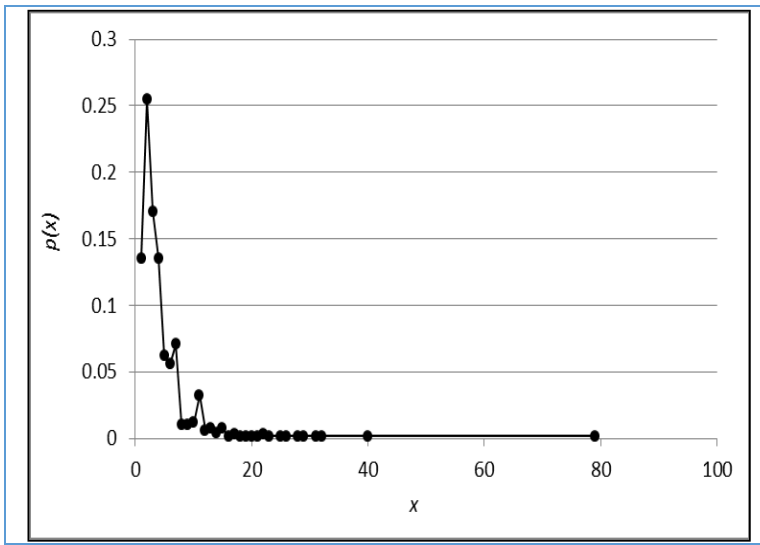

(a) non- $\log$ distribution

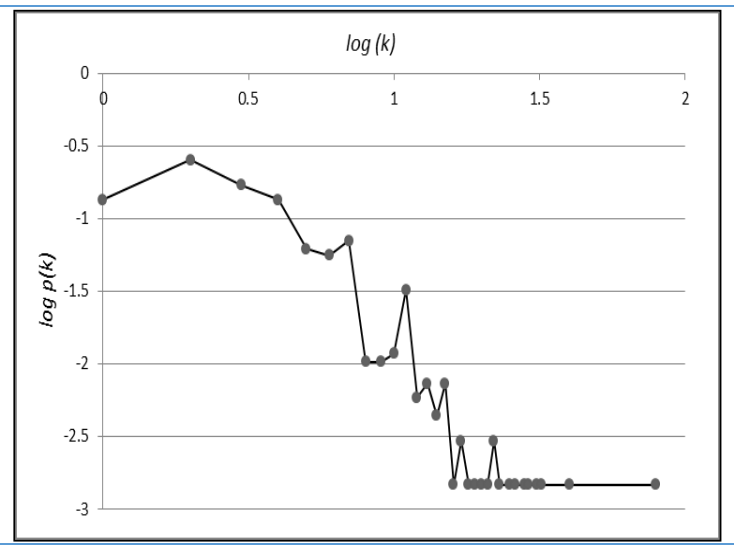

(b) $\log$ distribution

Fig. 3.Degree Centrality (DC) distribution

Those authors are the central actor in the network that connects the other actors. That phenomenon is related to scale-free distribution of author degree. Theoretically, this scale-free distribution of author degree is the power law distribution, Clauset et al. [20], is defined as:

$$
p(x) \sim x^{-\alpha}
$$

Where $x$ is the degree of node; $p(x)$ is the fraction of nodes in the network that have $x$ degree of centrality and $\alpha$ is constant parameter of the distribution known as the exponent or scaling parameter that usually lies in range of $2<\alpha<3$. Clauset et al. [20] address issues on how to test the power law distribution hypothesis, where the hypothesis are 1) data is generated from a power law distribution $\left(\mathrm{H}_{0}\right)$, and 2) data is not generated from a power law distribution $\left(\mathrm{H}_{1}\right)$.

The hypothesis was tested with goodness of fit statistics, using the bootstrapping procedure, suggest by Gillespie [21]. The hypothesis testing result accepted $\mathrm{H}_{0}$ with a $p$ value of 0.82 . This concluded that the degree of centrality distribution of Mathematics and Statistics related studies of Indonesian affiliation scholars follows the power law distribution. Estimated parameter using MLE (Maximum Likelihood Estimation) shows that the $\alpha$ is 3.13 .

Table 7 shows the micro level metric measures, the centrality measure of the top 10 authors. ITB's authors dominated with 8 out of top 10. This result is linear with the number of articles in Table 3 . Edy T. Baskoro from ITB, with the highest degree centrality (79). Based on Table 3, Edy T. Baskoro produced 30 articles. 
Table 7. Top 10 author centrality measures for co-authorship network of Indonesian affiliation scholars (in all networks) in Mathematics and Statistics related studies

\begin{tabular}{|c|c|c|c|c|c|}
\hline No & Authors & Institution & $\begin{array}{c}\text { Degree } \\
\text { Centrality }\end{array}$ & $\begin{array}{l}\text { Closeness } \\
\text { Centrality }\end{array}$ & $\begin{array}{c}\text { Betweenness } \\
\text { Centrality }\end{array}$ \\
\hline 1 & Baskoro, Edy Tri & ITB & 79 & 652 & 6.063 \\
\hline 2 & Baca, Martin & $\begin{array}{l}\text { Technical University } \\
\text { of Košice Slovakia }\end{array}$ & 40 & 681 & 4.405 \\
\hline 3 & Salman, A. N. M. & ITB & 32 & 735 & 5.152 \\
\hline 4 & Gunawan, Hendra & ITB & 31 & 746 & 4.360 \\
\hline 5 & Semanicova-Fenovcikova, Andrea & $\begin{array}{l}\text { Technical University } \\
\text { of Košice Slovakia }\end{array}$ & 29 & 692 & 6.675 \\
\hline 6 & Assiyatun, Hilda & ITB & 28 & 748 & 1.173 \\
\hline 7 & Pudjaprasetya, S. R. & ITB & 26 & 830 & 3.155 \\
\hline 8 & Astuti, Pudji & ITB & 25 & 793 & 6.808 \\
\hline 9 & Muchtadi-Alamsyah, Intan & ITB & 23 & 850 & 6.253 \\
\hline 10 & Miller, Mirka & ITB & 22 & 767 & 8.990 \\
\hline
\end{tabular}

There is one big cluster consisting of many authors with a relatively close distance between authors (Fig. 4). This network cluster shows that the members mostly come from ITB. Where ITB's coauthorship network consists of one big cluster and several small clusters. There are 60 ITB scholars in their co-authorship network in the Mathematics and Statistics related studies area.

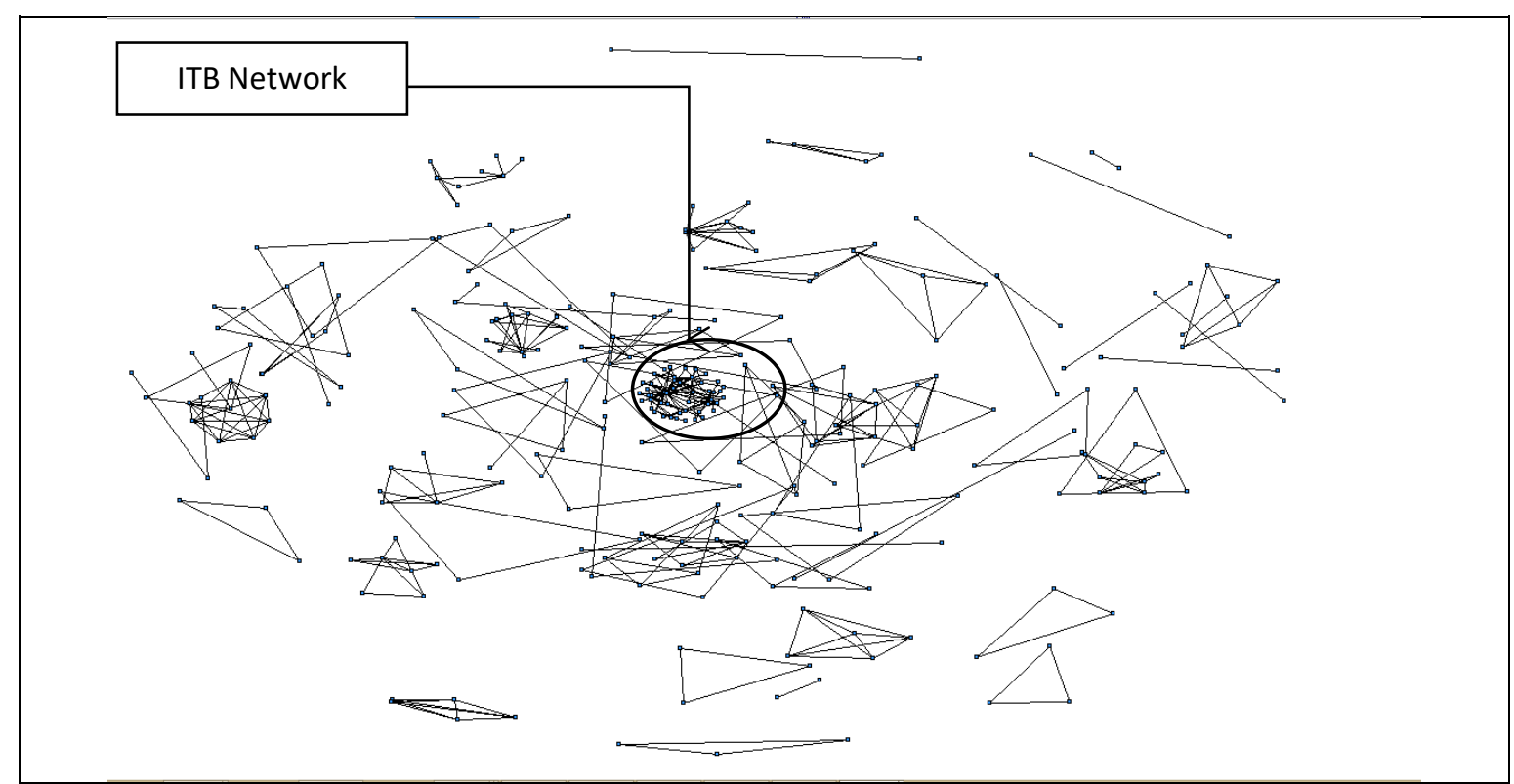

Fig. 4.Co-authorship network of all Indonesian affiliation scholars published on the Mathematics and Statistics studies area

Fig. 5 give the clear picture of co-authorship network for ITB scholars. There are 96 ITB scholars in their co-authorship network in the Mathematics and Statistics related studies area. Those scholars build a co-author relation with 210 scholars from 91 institutions around the world. The ITB's co-authorship network consist of one big cluster and several small clusters.

The big cluster consists of three central authors, Baskoro E.T., Salman, A.N.M., and Miller Minka. The clusters consist of 98 authors with 510 ties of co-authorship. Each central author is connected with the other networks within this cluster. There are three authors, Ryan, J., Maryanti, T.K., and Baca, Martin, that have direct connection with all of the central author. Ten authors in the network have direct connection with Baskoro and Salman. While another big cluster in ITB's network was made up of (Pudjaprasetya, S, R) (Gunawan, Hendra) as the central authors. Those cluster is quite big with more than 10 members of authors in each cluster and the others clusters are small with 2 to 5 members. 


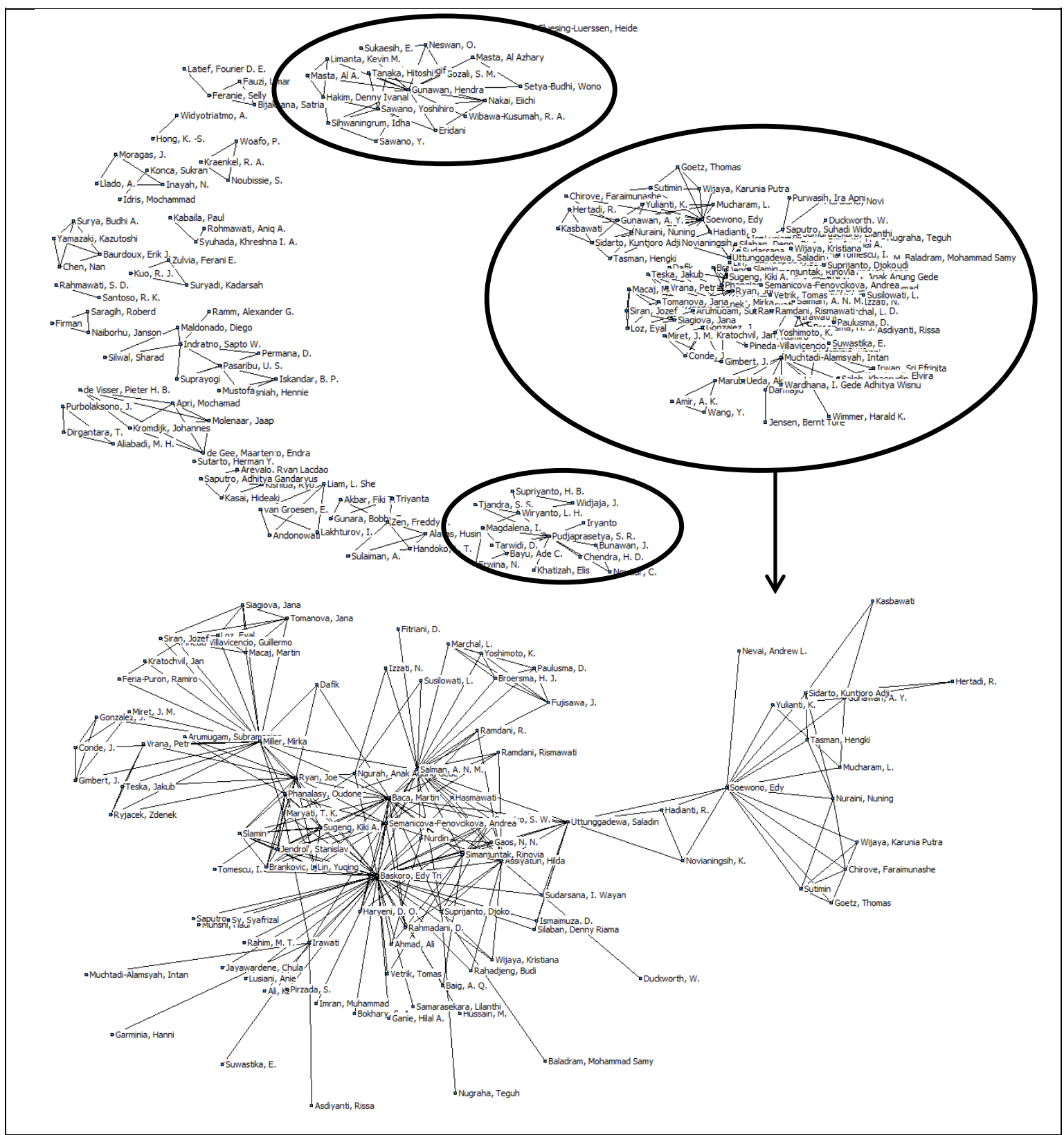

Fig. 5. Co-authorship network of ITB's scholar published on the Mathematics and Statistics studies area

Fig. 6 shows the co-authorship network where ITB is the central affiliation in the Indonesian affiliation network. ITB has direct relation with several big institution such as IPB, Airlangga University, University of Indonesia, etc. Meanwhile, ITB does not have direct relation with UGM (Gadjah Mada University). In general, there are two big network in the institutional level in Indonesia, the one that centered by ITB and the others is centered by UGM.

Fig. 7 shows the keyword density from an analysis of publications of Indonesian affiliation scholars. Keywords were taken from the indexed keyword of the articles. Keyword density was produced by the co-word analysis approach. Co-word analysis is based on the assumption that two keywords co-occurring within different articles are an indication of a link between the articles Wu \& Leu [22] and the assumption that they have the same meaning. Co-word analysis is widely used as a methodological approach to explore knowledge discovery in several fields of study. Surjandari et al. [23] mapped research themes of published articles by the top eight universities of Indonesia using co-word analysis. 


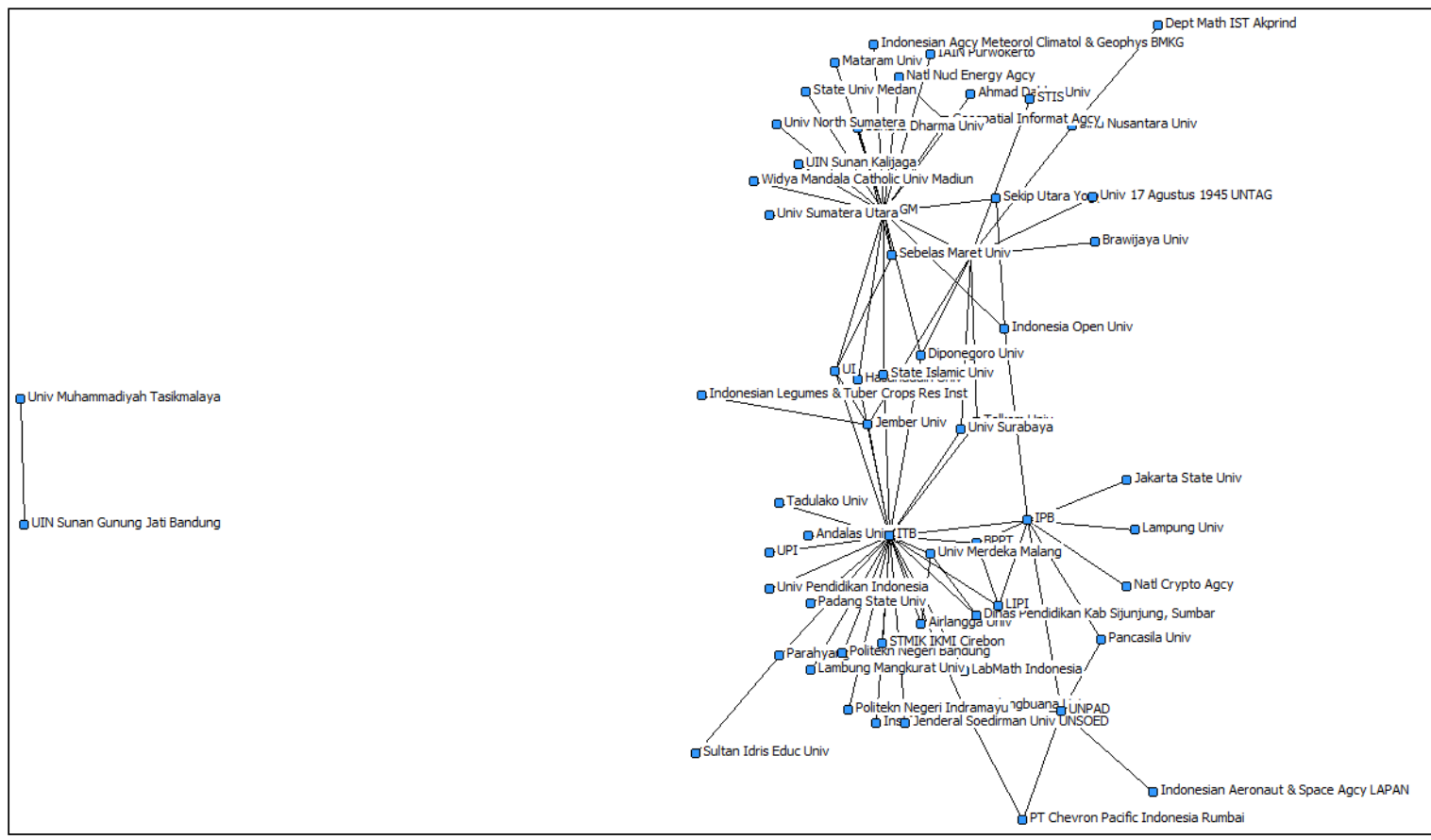

Fig. 6. Co-authorship affiliation network of ITB Indonesian scholars published on the Mathematics and Statistics studies area

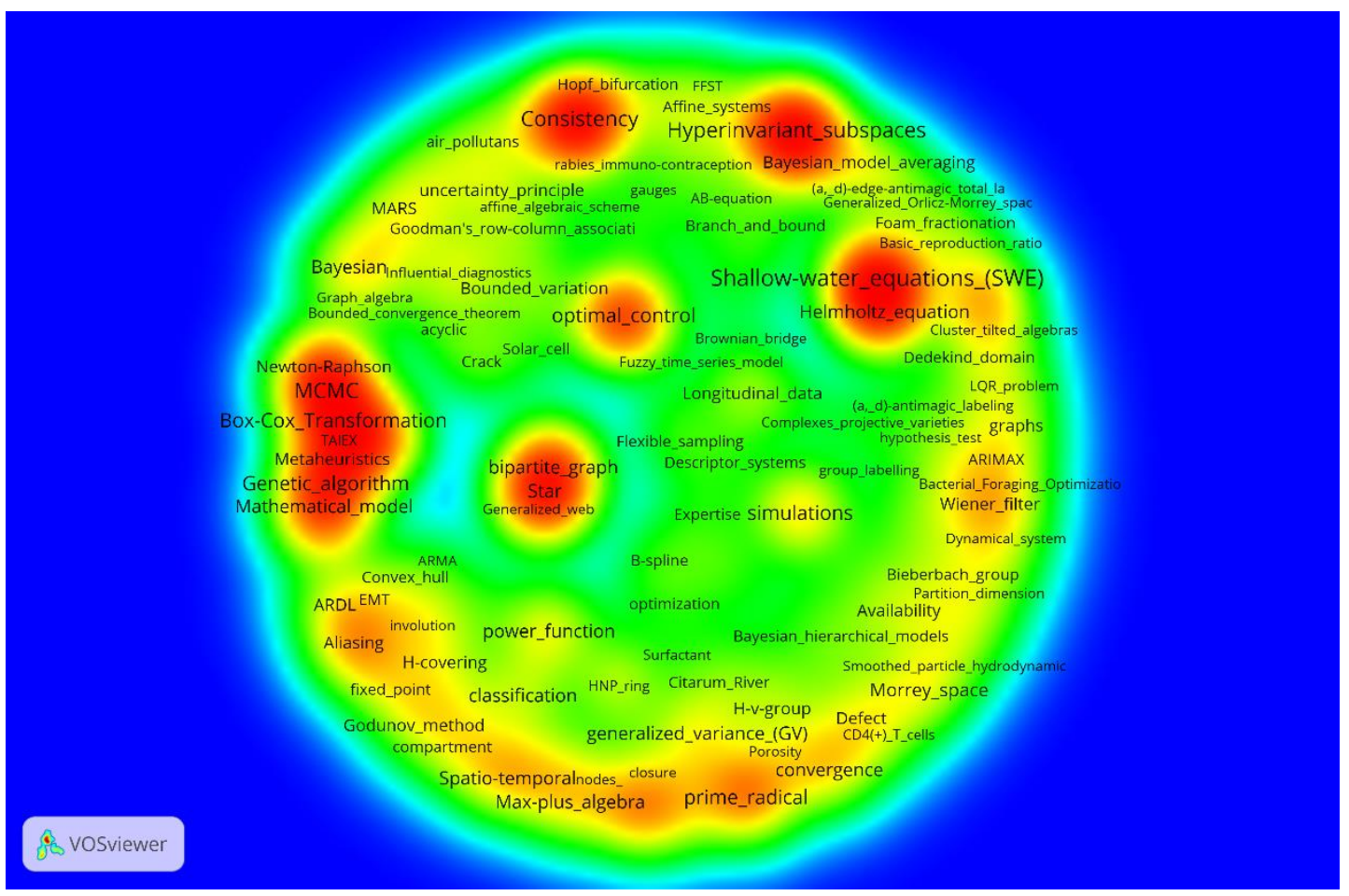

Fig. 7. Keyword density for Indonesian affiliation scholars published on the Mathematics and Statistics studies area

Fig. 7 is the visualization of co-word analysis using VosViewer software. Red color indicates high intensity of occurrence of the keyword. In general, there are $4 \mathrm{big}$ hotspots that consist of many of keyword that are correlated. In first hotspot consist of keyword that related to consistency test. The second hotspot is hyper-invariant subspace. Third is Shallow-water equation, and Helmholtz equation. Forth hotspot is related with, such as, Boxcox transformation, Newton-Raphson, Genetic Algorithm, and Mathematical model. 


\section{Conclusion}

Based on nine years data-set of international publications from Indonesian affiliated scholars in Mathematics and Statistics studies area, this research conducted a bibliometrics and scientometrics approach to examine the performance of Indonesian affiliation scholars in that area. This study showed some significant information about the performance of Indonesian affiliation authors and Indonesia academic institutions. Number of articles produced by Indonesian affiliated scholars are still low, only 426 articles during 2009-2017. Forty percent of authors are not affiliated with an Indonesia institution. ITB is the most productive institution with 138 publications from 255 authors. The most productive and efficient author has 30 articles and 79-degree centrality.

Based on macro-level measure of Social Network Analysis, co-authorship network from Indonesia affiliated scholars is a small-world network, where the network was sparse and fragmented. It was also dependent on several central authors to maintain the entire connection within the network. Based on degree distribution, the network is a scale-free network that indicates that some central authors have many connections with other authors while a majority of authors only collaborate with few authors. Coauthorship network in the Indonesian affiliation level shows there are two big cluster, ITB is the biggest network cluster, and UGM's cluster, as the second best-performed institution. Unfortunately, this two big institution are not have direct relation with each other. Co-word analysis found that there are four big cluster of keyword.

\section{Acknowledgment}

This study was supported by Research Center for Development of Science and Technology (Pappiptek) - Indonesian Institute of Sciences (LIPI), and we also thank Dr. Noel Taylor-Moore from Australian Volunteers International (AVI) for time and discussion.

\section{References}

[1] OECD and Asian Development Bank, Education in Indonesia Rising to the Challenge, 2015, doi: https://doi.org/10.1787/9789264230750-en.

[2] Statistics Indonesia (BPS), “Education Indicator, 1994-2017," Jakarta, 2017, available at: https://www.bps.go.id/statictable/2010/03/19\%2000:00:00/1525/indikator-pendidikan-1994-2017.html.

[3] M. Asadi, “"Information Theory" Research Trend: A Bibliometric Approach,” SLIS Connect., vol. 4, no. 1, 2015, doi: https://doi.org/10.18785/slis.0401.09.

[4] A. Van Raan, "Scientometrics: State of The Art," Saintometrics, vol. 38, no. 1, pp. 205-218, 1997, doi: https://doi.org/10.1007/BF02461131.

[5] A. Van Raan, "Advances in bibliometric analysis: research performance assessment and science mapping," in Bibliometrics. Use and abuse in the review of research performance, pp. 17-28, London: Portland Press Limited, 2014, available at: http://www.portlandpresspublishing.com/sites/default/files/Editorial/Wenner/WG_87/ WG_87_chapter\%203.pdf.

[6] S. Arunachalam, "Mathematics research in India today: What does the literature reveal?," Sci. 52 Ed., vol. 2, pp. 235-259, 2001, doi: https://doi.org/10.1023/A:1017915823434.

[7] I. M. Nadhiroh, M. N. Aidi, and B. Sartono, "Scientometrics Studies: Social Network Analysis of Indonesian International Publication on Chemistry," STI Policy Manag. J., vol. 13, no. 1, pp. 68-84, 2015, doi: https://doi.org/10.14203/STIPM.2015.40.

[8] H. Wen and Y. Huang, "Trends and performance of oxidative stress research from 1991 to 2010," Sci. 91 Ed., vol. 1, pp. 51-63, 2012, doi: https://doi.org/10.1007/s11192-011-0535-2.

[9] A. Abbasi and J. Altmann, "A social network system for analyzing publication activities of researcherse," Symp. Collect. Intell., vol. 76, pp. 49-61, 2010, doi: https://doi.org/10.1007/978-3-642-14481-3_5.

[10] L. C. Freeman, "Centrality in social networks conceptual clarification," Soc. Networks, 1st Ed., vol. 3, pp. 215-239, 1979, available at: https://www.bebr.ufl.edu/sites/default/files/Centrality\%20in\%20Social\%20 Networks.pdf. 
[11] W. Glänzel and A. Schubert, "Analysing Scientific Networks Through Co-Authorship", 2005, pp. 257-276, doi: https://doi.org/10.1007/1-4020-2755-9_12.

[12] J. P. Mena-Chalco, L. A. Digiampietri, F. M. Lopes, and R. M. Cesar, "Brazilian bibliometric co-authorship networks,” J. Assoc. Inf. Sci. Technol. 65 Ed., vol. 7, pp. 1424-1445, 2014, doi: https://doi.org/10.1002/ asi.23010.

[13] I. Alhaider, K. K. M. Ahmed, and B. M. Gupta, "Pharmaceutical research in the Kingdom of Saudi Arabia: A scientometric analysis during 2001-2010,” Saudi Pharm. Journal, 23 Ed., vol. 3, pp. 215-222, 2013, doi: https://doi.org/10.1016/j.jsps.2013.07.008.

[14] A. . Sorensen, A. Seary, and K. Riopelle, "Alzheimer's disease research: A COIN study using co-authorship network analytics,” Collab. Innov. Networks, 2nd Ed., vol. 4, pp. 6582-6586, 2010, doi: https://doi.org/ 10.1016/j.sbspro.2010.04.068.

[15] J. Li and Y. Li, "Patterns and evolution of co-authorship in China's humanities and social sciences," Sci. 102 Ed., vol. 3, pp. 1997-2010, 2015, doi: https://doi.org/10.1007/s11192-014-1471-8.

[16] E. Yan, Y. Ding, and Q. Zhu, "Mapping library and information science in China: A co-authorship network analysis," Sci. 83 Ed., vol. 1, pp. 115-131, 2010, doi: https://doi.org/10.1007/s11192-009-0027-9.

[17] J. W. Grossman, “The evolution of the mathematical research collaboration graph,” Congr. Numer., vol. 158, pp. 201-212, 2002, available at: Google Scholar.

[18] M. E. J. Newman, “Co-authorship networks and patterns of scientific collaboration,” Proc. Natl. Acad. Sci. USA, 101 Ed., vol. 1, pp. 5200-5205, 2004, doi: 10.1073/pnas.0307545100, doi: https://doi.org/10.1073/ pnas.0307545100.

[19] J. C. Brunson et al., "Evolutionary events in a mathematical sciences research collaboration network," Sci. 99 Ed., vol. 3, pp. 973-998, 2014, doi: https://doi.org/10.1007/s11192-013-1209-z.

[20] A. Clauset, C. . Shalizi, and M. E. J. Newman, "Power-law distributions in empirical data," SIAM Rev. 51 Ed., vol. 4, pp. 661-703, 2009, doi: https://doi.org/10.1137/070710111.

[21] C.S.Gillespie, “The poweRlaw package: Examples", available at: http://citeseerx.ist.psu.edu/viewdoc/ download;jsessionid=B48702D798971047F45733788D4D886C?doi=10.1.1.398.7935\&rep=rep1\&type=pdf.

[22] C. . Wu and H. J. Leu, "Examining the trends of technological development in hydrogen energy using patent co-word map analysis," Int. J. Hydrog. Energy, 39 Ed., vol. 33, pp. 19262-19269, 2014, doi: https://doi.org/10.1016/j.ijhydene.2014.05.006.

[23] I. Surjandari, A. Dhini, E. W. I. Lumbantobing, and I. Prawiradinata, "Big data analysis of Indonesian scholars publications: A research theme mapping," Int. J. Technol. 6th Ed., vol. 4, pp. 650-658, 2015, doi: https://doi.org/10.14716/ijtech.v6i4.1956. 